\title{
GA BASED SELECTIVE HARMONIC MINIMIZATION OF A 11 LEVEL CASCADED INVERTER USING PV PANELS
}

\author{
Kokila $\mathbf{R}^{1}$, F. T. Josh ${ }^{2}$ \\ ${ }^{I} P G$ scholar, EEE department, Karunya University, Tamil Nadu, India \\ ${ }^{2}$ Assistant Professor (SG), EEE department, Karunya University, Tamil Nadu, India
}

\begin{abstract}
A method for eliminating the lower order harmonics in a 11 level cascaded inverter is presented in this paper. The input for the multilevel inverter is taken from solar panels so that the input voltage will be varying with respect to time. Genetic algorithm is a selective harmonic minimization technique where the switching angles are calculated real time for a set of DC inputs from solar panels. These values of switching angles are applied to a 11 level cascaded H-bridge inverter. This paper will give details regarding the method along with the simulation results and calculation of Total Harmonic Distortion(THD). The target harmonics considered for minimization were $5^{\text {th }}, 7^{\text {th }}, 11^{\text {th }}$ and $13^{\text {th }}$ harmonics.
\end{abstract}

Keywords: GA, PV, Cascaded MLI, Selective Harmonic Minimization, THD.

\section{INTRODUCTION}

One of the most prominent issues that is encountered in case of high power converters is the presence of harmonics. For elimination of harmonics, several modulation methods are used. One of the most recent modulation method is Selective Harmonic Minimization Pulse Width Modulation (SHMPWM) method.

Selective harmonic elimination techniques for separate DC sources were proposed in [1],[5] according to which SHEPWM is an efficient modulation method for obtaining output waveforms with acceptable harmonic content. But there are certain drawbacks to SHEPWM method [2] such as the non-cancelled harmonics are not considered in the algorithm and could reach high amplitudes and the value of non-zeroed harmonics cannot be managed to get any optimization objective. [3] elaborates the elimination of harmonics in multilevel converters by solving the harmonic elimination equations by the method of resultant from elimination theory for the polynomial form of equations. In general case, if the voltage sources are unequal and varying with time, the solution set increases. As a result, the degree of polynomials increase and the time required to solve will also become more. As a result, the look-up tables will increase exponentially as the number of DC sources increase. So it needs to deal with extrapolation leading to time consuming algorithms. A method was proposed in [2] where the optimal switching angles were calculated using genetic algorithm. But it did not consider the variation of DC sources with respect to time. It was limited to equal DC sources. In [7] , a method in which the harmonics are eliminated using the theory of symmetric polynomials and resultants was developed. The problem with this method is that as the number of DC sources increases, the order becomes very high. This leads to computational complexity. The calculation of switching angles was calculated online using Newton Raphson method in [4]. The limitations of this paper is that it considers that the voltage sources will be varying, but they have the same value at the same time. They vary keeping the same relative value. All the above papers considered only the case of equal DC sources. It did not consider the variation of DC sources with respect to time. In practical cases, the variation of DC sources with respect to time has to be considered. So in this work, the DC sources feeding the multilevel inverters are taken from solar panels, the value of input voltages of which are considered to be varying with respect to time. The switching angles are adapted to this variation of DC sources. Genetic Algorithm(GA) is used to obtain the switching angles that corresponds to real values of DC sources. Here 11 level multilevel inverter is taken into consideration. The target harmonics to be reduced are $5^{\text {th }}, 7^{\text {th }}, 11^{\text {th }}$ and $13^{\text {th. }}$

This paper is organized as follows. In section II, the set of equations for harmonic minimization is described and GA is introduced. In section III, GA based control is explained. Section IV gives the simulation results of 11 level multilevel inverter using GA. The value of THD and lower order harmonics are calculated.

\section{PROBLEM DEFINITION}

In general case, the variation of DC sources with respect to time also has to be considered. For example, if we consider the output of solar panels, fuel cells, batteries etc. to be given as the input of multilevel inverter, their variations should be taken into consideration. The corresponding switching angles given by the algorithm has to respond to this variation of DC 
sources. In this proposed method, GA is used to obtain the angles corresponding to real values of DC sources.

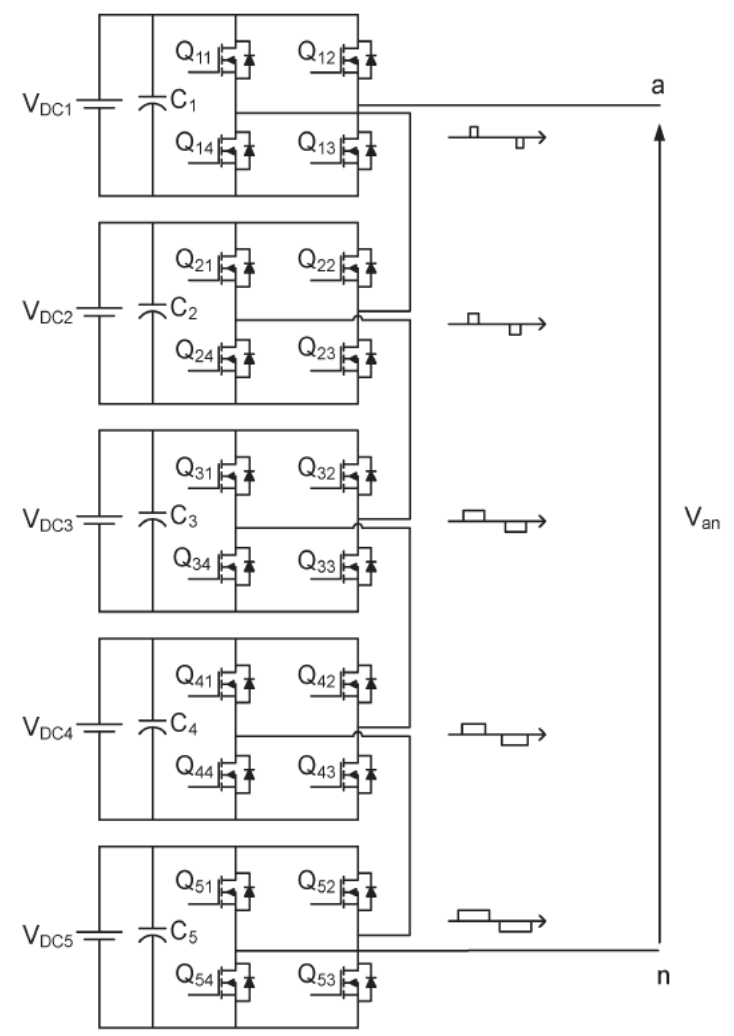

Fig-1: 11 level cascaded inverter

Fig 1 shows the 11 level cascaded inverter. It requires 5 DC inputs, in this case, it is taken from solar panels. The output voltage equations corresponding to Fig 2 can be expressed as the following equation

$$
\begin{gathered}
V_{a n}(\omega t)=\sum_{n=1,3,5,7, \ldots}^{\infty} \frac{4}{\pi n} \cdot\left(V_{d c 1} \cos \left(n \theta_{1}\right)+V_{d c 2} \cos \left(n \theta_{2}\right)+\right. \\
\left.V_{d c 3} \cos \left(n \theta_{3}\right)+V_{d c 4} \cos \left(n \theta_{4}\right)+V_{d c 5} \cos \left(n \theta_{5}\right)\right)
\end{gathered}
$$

Where $V_{d c 1}, \ldots . ., V_{d c 5}$ - Input DC sources

$$
\begin{gathered}
\theta_{1}, \ldots \ldots ., \theta_{5}-\text { Output angles } \\
V_{a n} \text { - Inverter output voltage }
\end{gathered}
$$

The proposed approach works as follows:-The input voltages from the solar panels will be varying with respect to time. Genetic algorithm works to obtain the switching angles corresponding to the variation of DC sources in such a way that minimum total harmonic distortion is obtained. It also emphasizes in reduction of lower order harmonics such as $5^{\text {th }}$, $7^{\text {th }}, 11^{\text {th }}$, and $13^{\text {th }}$.

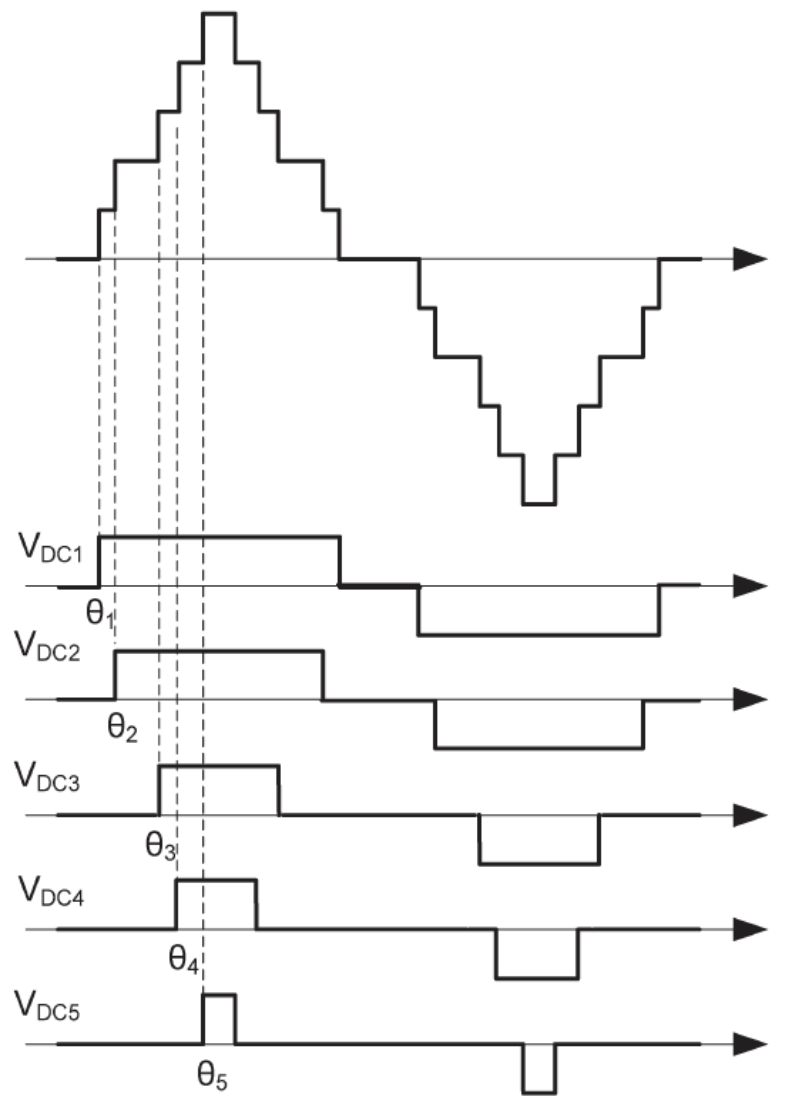

Fig-2:11 level inverter output waveform

\section{GA BASED HARMONIC MINIMIZATION}

A genetic algorithm (GA) is a stochastic search method shown to be well suited for problems where many global minimum and/or highly dimensional search spaces are possible. Each individual of a set has an associated cost value, referred to as "fitness function" that is a measure of how well this individual performs in the population. In previous works, analytical solutions were found partially in the range space of input voltage variation; however, this approach still uses GA first, because this range is used to calibrate it to perform in the range where there is no analytical solution. The basic continuous GA execution flow is shown in Fig 3.

Under the variations of DC sources, it is necessary to maintain the fundamental output voltage and to cancel out the lower order harmonics. Here the harmonics $5^{\text {th }}, 7^{\text {th }}, 11^{\text {th }}$, and $13^{\text {th }}$ harmonics are the required harmonics to be cancelled. The triplen harmonics such $3^{\text {rd }}$ and $9^{\text {th }}$ harmonics are not considered because in three phase application, it is cancelled in the line voltage. 


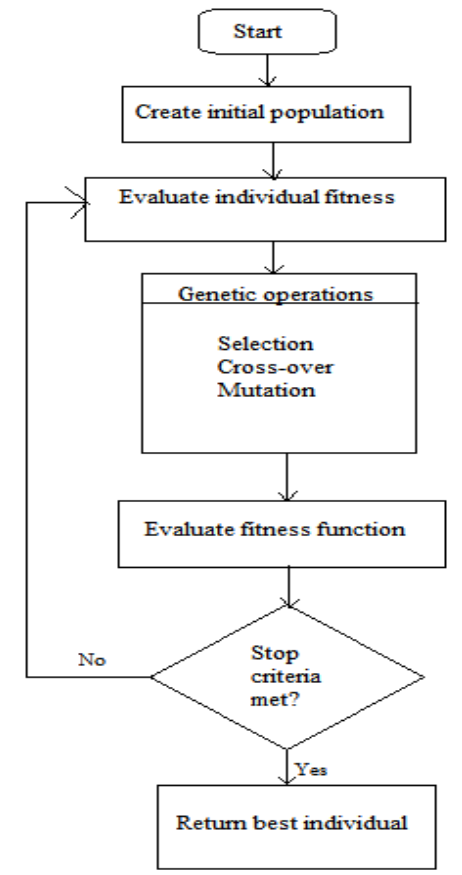

Fig-3: Flowchart for GA execution

The equations for the fundamental voltage, $5^{\text {th }}, 7^{\text {th }}, 11^{\text {th }}$ and $13^{\text {th }}$ harmonics are given below

$$
\begin{aligned}
& V_{\text {fund }}=\frac{4}{\pi}\left[V_{d c 1} \cos \left(\theta_{1}\right)+V_{d c 2} \cos \left(\theta_{2}\right)+\ldots .+V_{d c 5} \cos \left(\theta_{5}\right)\right] \\
& V_{5 t h}=\frac{4}{5 \pi}\left[V_{d c 1} \cos \left(5 \theta_{1}\right)+V_{d c 2} \cos \left(5 \theta_{2}\right)+\ldots .+V_{d c 5} \cos \left(5 \theta_{5}\right)\right] \\
& V_{7 t h}=\frac{4}{\pi}\left[V_{d c 1} \cos \left(7 \theta_{1}\right)+V_{d c 2} \cos \left(7 \theta_{2}\right)+\ldots+V_{d c 5} \cos \left(7 \theta_{5}\right)\right]
\end{aligned}
$$

$V_{11 t h}=\frac{4}{11 \pi}\left[V_{d c 1} \cos \left(11 \theta_{1}\right)+V_{d c 2} \cos \left(11 \theta_{2}\right)+\ldots+V_{d c 5} \cos \left(11 \theta_{5}\right)\right]$

$$
V_{13 t h}=\frac{4}{13 \pi}\left[V_{d c 1} \cos \left(13 \theta_{1}\right)+V_{d c 2} \cos \left(13 \theta_{2}\right)+\ldots+V_{d c 5} \cos \left(13 \theta_{5}\right)\right]
$$

The equations (2) to (6) are given as the equations to solve the angles using GA. The fundamental voltage is taken as $230 \mathrm{~V}$ rms. The equations (3) to (6) are equated to zero in order to eliminate them. [6] gives the objective function for the GA as given in equation(7)

$$
\begin{aligned}
& f\left(V_{\text {fund }}, V_{5 t h}, V_{7 t h}, V_{11 t h}, V_{13 t h}\right)=k_{1}\left|V_{\text {fund }}-230\right|+k_{2} \\
& \left|V_{5 t h}\right|+k_{3}\left|V_{7 t h}\right|+k_{4}\left|V_{11 t h}\right|+k_{5}\left|V_{13 t h}\right|
\end{aligned}
$$

The values for $k_{2}, k_{3}, k_{4}, k_{5}$ are generally taken greater than $k_{1}$. It can be taken as multiples of 10 . Calculations were made for switching angles that correspond to the randomly taken values of DC sources. The values of coefficients used in Equation (7) were found through trial and error runs of the algorithm. They allow the fundamental to be kept very close to $230 \mathrm{~V}$ while keeping harmonics close to zero. The GA program was written using Matlab R2010a. The termination criteria was given in such a way that the number of iterations is 100 . So the algorithm stops at $100^{\text {th }}$ generation and it will

\begin{tabular}{|c|c|}
\hline $\begin{array}{l}\text { Input Voltages(V) } \\
{\left[{ }_{d c 1} V_{d c 2} V_{d c 3} V_{d c 4} V_{d c 5}\right]}\end{array}$ & $\begin{array}{l}\text { Output Angles }\left({ }^{0}\right) \\
{\left[\theta_{1} \theta_{2} \theta_{3} \theta_{4} \theta_{5}\right]}\end{array}$ \\
\hline$\left[\begin{array}{llllll}40 & 41 & 42 & 43 & 44\end{array}\right]$ & $\begin{array}{l}{\left[\begin{array}{lll}0.182 & 21.709 & 44.615 \\
60.274 & 88.363\end{array}\right]}\end{array}$ \\
\hline$\left[\begin{array}{lllll}40 & 42 & 43 & 44 & 45\end{array}\right]$ & $\begin{array}{l}{\left[\begin{array}{lll}1.191 & 23.622 & 45.623 \\
59.565 & 74.464\end{array}\right]}\end{array}$ \\
\hline$\left[\begin{array}{lllll}40 & 42 & 43 & 44 & 46\end{array}\right]$ & 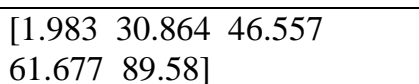 \\
\hline$\left[\begin{array}{llllll}4 & 42 & 43 & 44 & 45\end{array}\right]$ & $\begin{array}{l}{\left[\begin{array}{lll}0.446 & 27.372 & 37.528 \\
57.359 & 82.694\end{array}\right]}\end{array}$ \\
\hline$\left[\begin{array}{lllll}42 & 43 & 44 & 45 & 46\end{array}\right]$ & 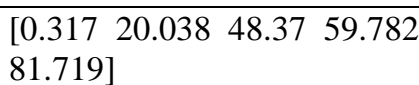 \\
\hline$\left[\begin{array}{llllll}43 & 44 & 46 & 47 & 48\end{array}\right]$ & 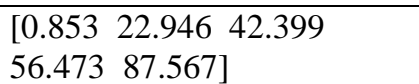 \\
\hline$\left[\begin{array}{lllll}4 & 45 & 46 & 47 & 48\end{array}\right]$ & 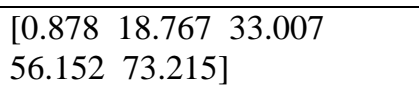 \\
\hline
\end{tabular}
return the best individual as the end product. Table 1 shows the parameters used for running GA.

Table-1: Parameters for GA

\begin{tabular}{|l|l|}
\hline Population size & 100 \\
\hline Number of generations & 100 \\
\hline Stall generations & 50 \\
\hline Crossover fraction & 0.8 \\
\hline
\end{tabular}

Table-2: Dataset obtained through GA run 
Calculations were made for switching angles that correspond to the randomly taken values of DC sources. Table 2 represents the dataset obtained through GA run for different sets of input voltages.

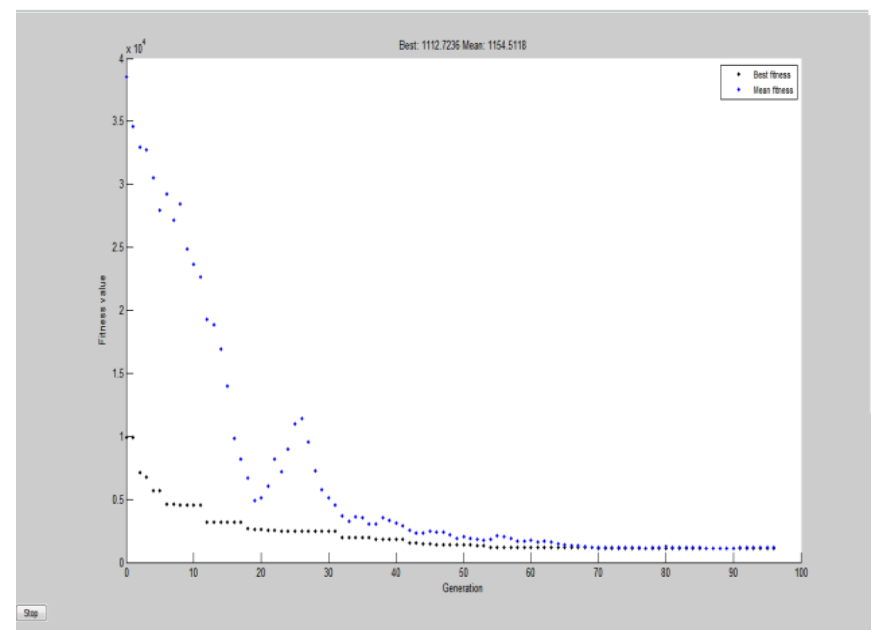

Fig-4: GA fitness plot for 100 generations

Fig 4. shows the fitness plot of GA after 100 generations. The best and the mean values of fitness functions were obtained.

Best fitness value: 1112.7346

Mean fitness value: 1154.5118

\section{SIMULATION RESULTS AND ANALYSIS}

In this section, the simulation results of 11 level cascaded inverter is presented. The simulation is carried out using MATLAB/SIMULINK software by the switching angles obtained from Table 2. The output waveforms and the FFT analysis were also carried out. The input is given from five different solar panels. The solar panels were modeled using the equations as given below.

The photon current is given by

$$
I_{p h}=\left[I_{s c r}+K_{i}(T-298)\right] S / 1000
$$

Where $I_{s c r}$ is the short circuit current

$K_{i}$ is the short circuit current temperature co-efficient

$\mathrm{T}$ is the module operating temperature

$\mathrm{S}$ is $\mathrm{PV}$ module illumination

The module reverse saturation current is

$$
I_{r s}=I_{s c} /\left[\exp \left(q V_{o c} / N_{s} K A T\right)-1\right]
$$

Where $\mathrm{q}$ is electron charge

$$
V_{o c} \text { is the open circuit voltage }
$$

$N_{s}$ is number of cells connected in series

$\mathrm{K}$ is Boltzman constant

$\mathrm{A}$ is ideality factor

The module saturation current is

$$
I_{s}=I_{r s}\left[T / T_{r}\right]^{3} \exp \left[\left(q E_{g o} / A K\right)\left(1 / T_{r}-1 / T\right)\right]
$$

Where $T_{r}$ is the reference temperature

$E_{g o}$ is the bandgap

The output current of PV module is

$$
I=N_{p} I_{p h}-N_{p} I_{s}\left[\frac{\exp q\left(V+I R_{s}\right)}{N_{s} A K T}-1\right]
$$

$N_{p}$ is the number of parallel connected cells

$R_{s}$ is series resistance

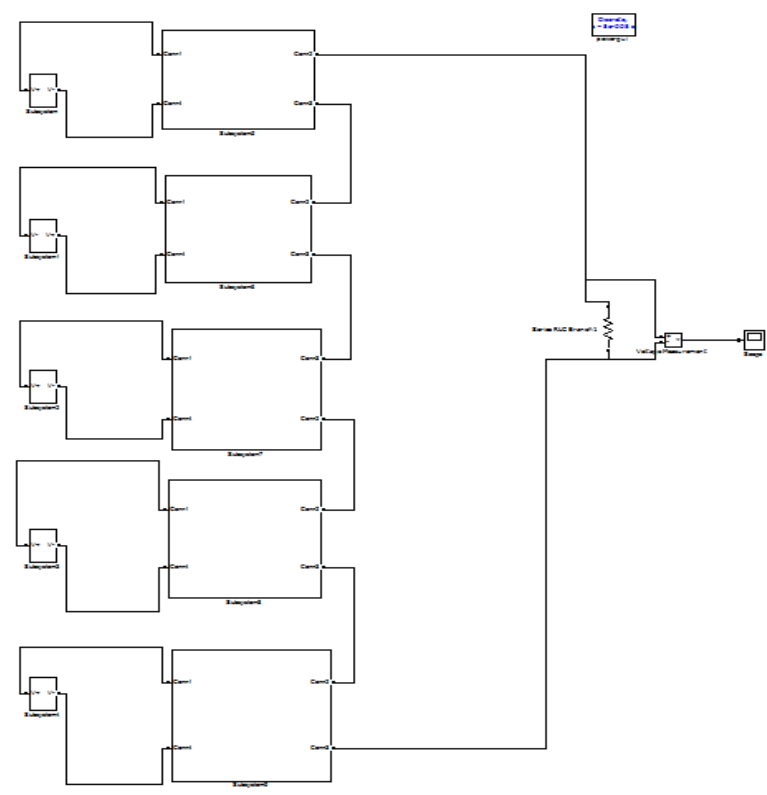

Fig-5: Simulation Diagram of 11 level inverter 


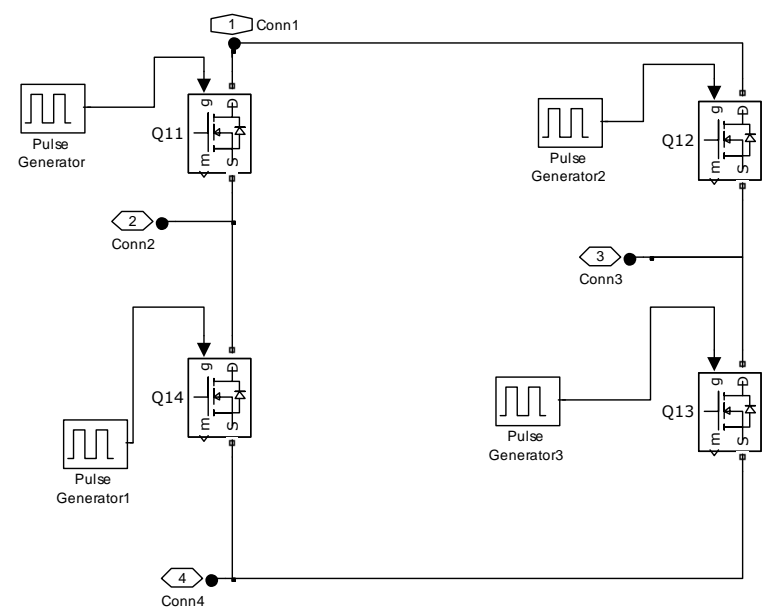

Fig-6: Subsystem of multilevel inverter

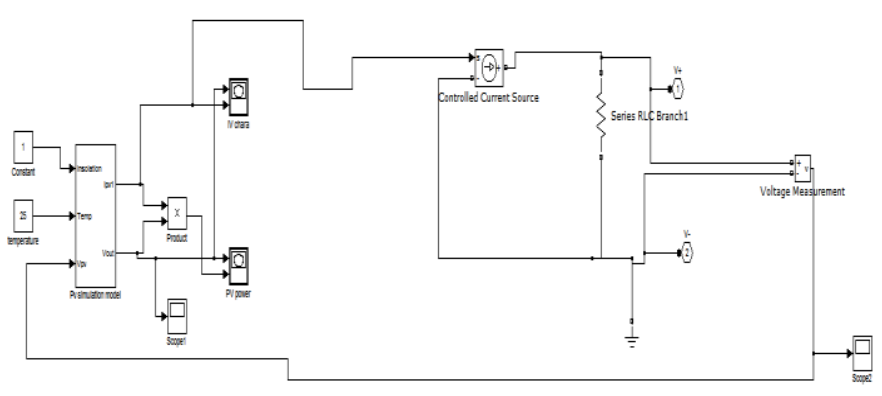

Fig-7: Subsystem of solar panel

The output voltage and THD analysis for 11 level inverter using solar panel inputs are shown in Fig 8 and Fig 9 respectively.

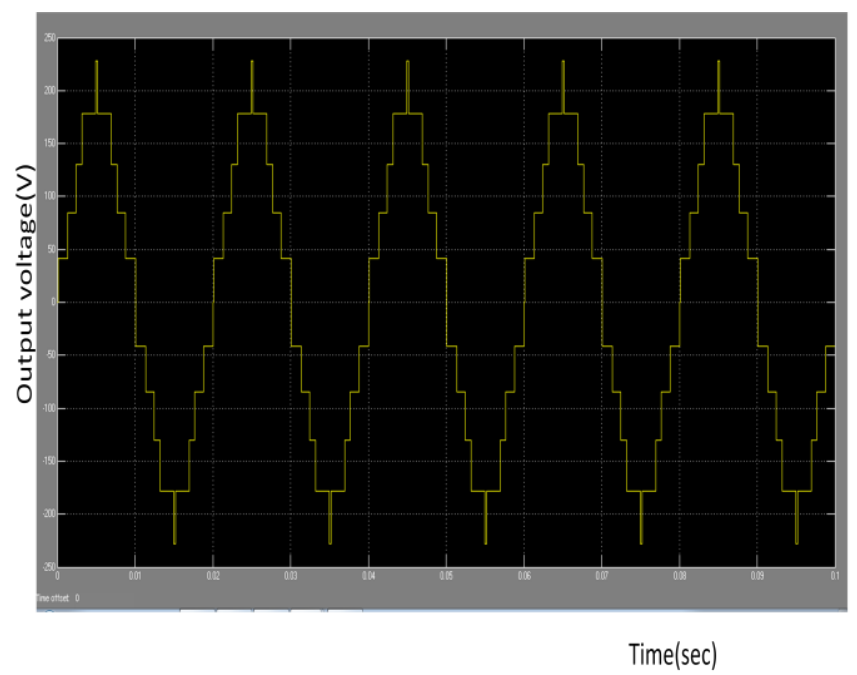

Fig-8: Output waveform of multilevel inverter

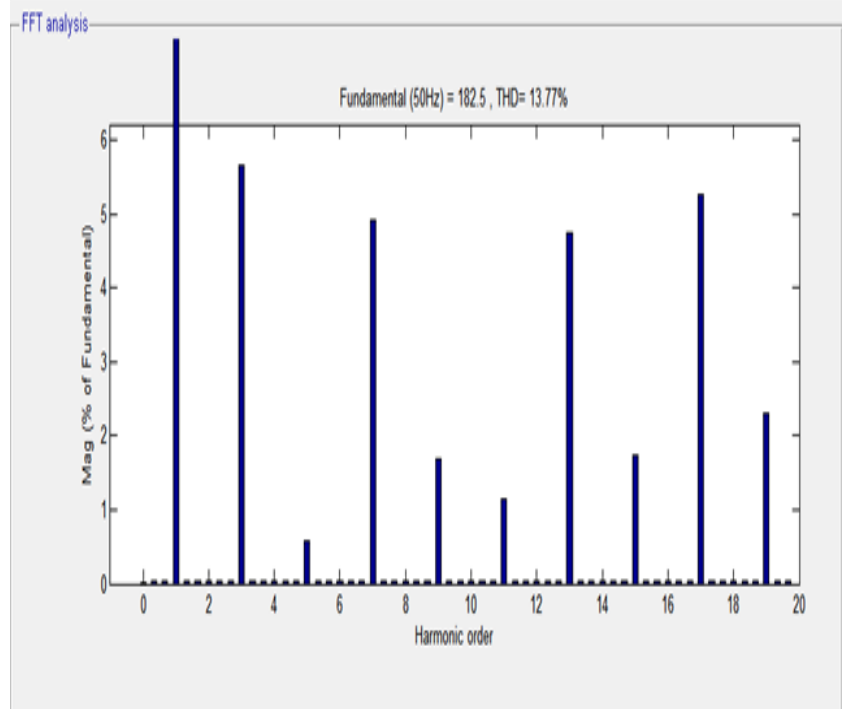

Fig-9: FFT analysis

From the FFT analysis, it can be seen that the THD is less and the lower order harmonics are minimized.

The value of THD and lower order harmonics are given in table 3.

Table-3: Parameters obtained from the FFT analysis of output of GA controller

\begin{tabular}{|l|l|}
\hline Parameter & Value \\
\hline Fundamental Voltage $V_{\text {fund }}(\mathrm{V})$ & 182.5 \\
\hline THD $(\%)$ & 13.77 \\
\hline $5^{\text {th }}$ Harmonic $V_{5}(\%)$ & 0.57 \\
\hline $7^{\text {th }}$ Harmonic $V_{7}(\%)$ & 4.91 \\
\hline $11^{\text {th }}$ Harmonic $V_{11}(\%)$ & 1.14 \\
\hline $13^{\text {th }}$ Harmonic $V_{13}(\%)$ & 4.76 \\
\hline
\end{tabular}

\section{CONCLUSIONS}

This paper presents an approach for real time computation of switching angles using GA. The solutions were found in real time using genetic algorithms to obtain a data set. GA was also used so as to explore the advantages of approximate solutions. The 11 level inverter whose inputs were taken from PV panels was simulated and the output was obtained. The THD analysis was also carried out. It is observed that the value of THD was very low. It also reduces the lower order harmonics such as $5^{\text {th }}, 7^{\text {th }}, 11^{\text {th }}$ and $13^{\text {th }}$. Future work points in the direction of implementation and performance evaluation over a greater number of angles. This would allow for harmonic control while keeping the switching frequency minimum and complying with THD standards. The literature 
review also pointed the possibility of determining what the minimum number of angles needed is in order to comply with certain THD level. Future work also emphasises on the real time hardware implementation of the GA tuned ANN technique using adSpace or DSP platform.

\section{REFERENCES}

[1]. J. Napoles, J. I. Leon, R. Portillo, L. G. Franquelo, and M. A. Aguirre, "Selective harmonic mitigation technique for high-power converters," IEEE Trans. Ind. Electron., vol. 57, no. 7, pp. 2315-2323, Jul. 2010.

[2]. J. N. Chiasson, L. M. Tolbert, K. J. McKenzie, and Z. Du, "A unified approach to solving the harmonic elimination equations in multilevel converters," IEEE Trans. Power Electron., vol. 19, no. 2, pp. 478-490, Mar. 2005.

[3]. J. N. Chiasson, L. M. Tolbert, K. J. McKenzie, and Z. Du, "Elimination of harmonics in a multilevel converter using the theory of symmetric polynomials and resultants," IEEE Trans. Control Syst. Technol., vol. 13, no. 2, pp. 216-223, Mar. 2005.IEEE Trans. Control Syst. Technol., vol. 13, no. 2, pp. 216-223, Mar 2005.

[4]. T. Tang, J. Han, and X. Tan, "Selective harmonic elimination for a cascade multilevel inverter," in Proc. IEEE Int. Symp. Ind. Electron., Jul. 2006, vol. 2, pp. 977-981.

[5]. J. Chavarria, D. Biel, F. Guinjoan, C. Meza, and J. J. Negroni, "Energybalance control of PV cascaded multilevel grid-connected inverters under level-shifted and phase-shifted PWMs," IEEE Trans. Ind. Electron.,vol. 60, no. 1, pp. 98111, Jan. 2013.

[6]. Faete Filho, Helder Zandonadi Maia, Tiago H.A. Mateus, Burak Ozpineci, Leon M. Tolbert and Joao O. P. Pinto, "Adaptive Selective Harmonic Minimization Based on ANNs for Cascade Multilevel Inverters With Varying DC Sources", IEEE Transactions on Industrial Electronics, Vol. 60, No.5, pp. 1955 - 1962, May 2013.

[7]. Chiasson J. N, Ozpineci B, and Tolbert L . M, "Harmonic optimization of multilevel converters using genetic algorithms," IEEE Power Electron Lett., vol. 3, no. 3, pp. 9295,Sep.2005.

[8]. T.Ikegami,T.Maezono,F.Nakanishi, Y. Yamagata and K.Ebihara, "Estimation of equivalent circuit parameters of PV module and its application to optimal operation of PV system,"Elsevier solar energy materials and solar cells,67(2001),pp.389-395,Jan 2001.

\section{BIOGRAPHIES}

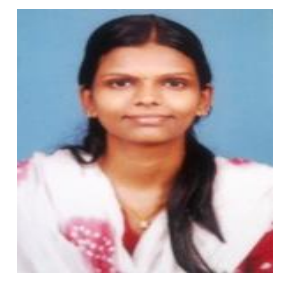

Kokila $\mathbf{R}$ completed her B.Tech degree in Electrical and Electronics Engineering at LBS College of Engineering, Kasaragod. She is pursuing M.Tech in Power Electronics and Drives at Karunya University, Coimbatore. Her area of interest include Multilevel inverter, soft

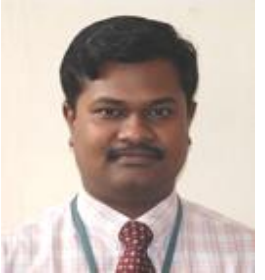

Mr. F. T. Josh completed his B. E in Electrical and Electronics Engineering in 2000. He completed his M.E degree in Power Electronics and Drives. He has 12 years of experience in teaching. $\mathrm{He}$ is currently working as Assistant Professor(SG) in Karunya University, Coimbatore. His areas of interest include Multilevel inverters, soft computing etc.

computing etc. 